\title{
EL MAR, ABSOLUTO LITERARIO. LA INFLUENCIA DEL ROMANTICISMO ALEMÁN EN LA RENAIXENÇA CATALANA
}

\author{
THE SEA, LITERARY ABSOLUTE. THE GERMAN \\ ROMANTICISM INFLUENCE IN THE CATALAN RENAIXENÇA
}

\section{María Teresa CARO VALVERDE}

\author{
Universidad de Murcia \\ maytecar@um.es
}

Resumen: La teoría literaria de la Renaixença sobre el vitalismo de la facultad creadora procede de la poética de la imaginación del Romanticismo alemán que indagó en el absoluto literario a través de la contemplación del mar como espejo infinito del artista. Caso ejemplar es la obra de Maragall.

Abstract: Literary theory of the Renaixença on the vitalism of the creative faculty comes from the poetic of the imagination of German Romanticism which investigated in literary absolute through the contemplation of the sea as the artist infinite mirror. Case in point is the work of Maragall.

Palabras clave: Absoluto literario. Mar Mediterráneo. Renaixença. Romanticismo alemán. Joan Maragall.

Key words: Literary absolute. Mediterranean Sea. Renaixença. German Romanticism. Joan Maragall. 


\section{EL MAR EDUCA LA MIRADA INTERIOR}

Este estudio investiga la inspiración que la naturaleza del mar Mediterráneo aportó a la poética de la imaginación como absoluto literario ideada en el Sturn und Drang y el modo en que fue introducida en la literatura española por los poetas de la Renaixença catalana gracias a las primeras traducciones de las obras de los grandes ideólogos del movimiento romántico y a su indagación en la teoría del genio poético para revitalizar el ingenio de su pueblo, del cual el Mare Nostrum es símbolo sublime y, por tanto, ejemplo indispensable de las afinidades electivas entre los artistas de ambos movimientos.

El mar de los poetas románticos es una utopía de sentido figurado en cuyos regazos buscan el vaivén de lo eterno residual. El pasaje marino, naturaleza donde confluyen lo acabado y lo inacabado, inspira su mirada interior como un espejo de lo que Bachelard (1965: 168) denomina «inmensidad íntima», pues en la poética de su espacio se desata la pasión humana que no imita sino que penetra la obra natural para entender su modo de operar orgánico y vivo hacia la plenitud y variedad interminables. Es por ello que Cansinos Assens, admirador y traductor de las obras completas de Goethe, en su ensayo «El influjo del mar en la lírica» (Cansinos Assens, 1932: 19-32) apreció en sus aguas el cántico ininterrumpido que de modo natural inspira el ritmo y la armonía artísticos: «Siempre que el mar lleva su flujo y reflujo a la poesía, apuntan las polifonías movidas y largas. Inspira onomatopeyas sonoras, dulces, o bravas cadencias, según que venga del lado de su calma o de su tempestad, pero siempre superiores a las que puede inspirar la tierra» (Cansinos Assens, 1932: 20).

El concepto de absoluto literario nació de la poética de la imaginación teorizada por un grupo de artistas filólogos del Romanticismo alemán —los hermanos Schlegel, Novalis y Schelling - (Lacoue-Labarthe \& Nancy, 1978) que encontraron en la obra de Goethe la visión utópica del mar que suscita el salto del gusto estético hacia el genio creativo. Desde que en su viaje a Italia Goethe aprendiera que la patria de la antigüedad grecolatina no era la tierra sino el mar y su utopía, sensibilizó todavía más su mirada interior ante la naturaleza sensual e infinita. Su magisterio artístico abrió el camino a los románticos alemanes e ingleses para que contemplasen el mar desde las profundidades del sentimiento y de lo onírico, y se explorasen a sí mismos con la mirada invertida hacia adentro. El punto de vista sumergido, el de los narcisos-atlantes que convierten el acto de la contemplación estética en una metacontemplación especular, es el que define su teoría de la literatura. 
El mar alegoriza la experiencia inconmensurable tanto en su faceta apolínea (bella armonía) como dionisíaca (sublime infinito). A juicio de Goethe, la inspiración procede de Homero, quien aprendió la lección de arte de su primera maestra: la naturaleza mediterránea. El poeta buscó en ella el espíritu de todo. Y, por tanto, nos dio ejemplo para no caer en la burda imitación de los clásicos como modelos naturalistas y aplicar la imaginación artística a la mirada interior ante el paisaje. El espíritu del mar, armonioso e infinito, es la inspiración homérica realzada por el Romanticismo. La educación estética se desarrolló ante la experiencia perceptiva de lo sublime, la cual, por su condición siniestra a la lógica socrática, había sido silenciada desde la clasicidad apolínea que había mesurado nuestras letras durante dos milenios. Así que quienes vuelvan el rostro a la Grecia presocrática en busca de la vitalidad creativa del arte han de rescatar lo sublime como una visión abismada, como una Atlántida cuya belleza trasluce el entretiempo del olvido que dulcifica el dolor vital patéticamente asumido, pues, en efecto, las aguas del Mediterráneo fueron para los griegos el símbolo del origen diferido que invita al viaje de la imaginación (Caro Valverde y Morin, 2008).

La interdependencia de ambas facetas hace caro el ideal: Grecia representaba un máximo de arte nacional que el Romanticismo alemán no podía imitar de manera servil; antes bien, debía asimilarlo en amistad, esto es, en su gesto creativo. Romantizar aquel momento «clásico», de máximo esplendor, se les presentaba así como la exigencia de entregarse a la alta tensión del entretiempo, donde lo pasado se proyecta hacia el futuro y el presente se vive como un instante de mediación entre dos sueños, el de un pasado glorioso y el de un futuro a su imagen por venir. El camino hacia la excelsa cultura del Mediterráneo es una aventura en el tiempo de trágica meta, porque la perfección humana nunca acaba. El ideal griego es así un espejo de ironía: los románticos que se miran en él solo ven devuelta la imagen del pasado, el abismo de inanidad de las ruinas. Tal es el riesgo del proyecto poético donde Oriente y Occidente se reconciliarían mesiánicamente una vez que lo mediterráneo descubriera su espíritu amigo.

La teoría literaria del Romanticismo surgió en Jena para educar la creación artística que ellos entendían como «Genio» a fin de depurar estéticamente y consolidar políticamente el espíritu del pueblo alemán a través de la visión sentimental de la naturaleza. Winckelmann, Lessing, Schiller, Schelling, y a la cabeza Goethe, resucitaron la antigua Hélade como ideal, y, todavía más allá, Novalis, F. Schlegel y Hölderlin la incorporaron como absoluto literario o vitalidad del arte. Paralelamente, en Inglaterra, Wordsworth y Coleridge desarrollaron un concepto de lo imaginario creativo importado 
de Fitche y de Schelling con vistas a cultivar una comprensión orgánica del mundo. Y la romantización del espíritu griego presocrático volvió a encontrar en Nietzsche un defensor portentoso desde que en El origen de la tragedia anunciara un vitalismo de naturaleza dionisíaca como vertiente patética de lo sublime nacido de la verdad de las paradojas.

Tarde fue asumida por los artistas españoles esta romantización de la cultura griega. Rukser ha señalado la reticencia que nuestra cultura mantuvo frente al helenismo hasta la segunda mitad del siglo XIX. La tradición educativa escolástica fue responsable de que, con la llegada del Renacimiento, en España solo se valorara la antigüedad romana como base de la cultura mediterránea, aspecto recrudecido con el academicismo neoclásico. Los pensadores y artistas griegos no podían tener abrigo bajo la sombra alargada de la Contrarreforma, antes bien su paganismo era anatema y su filosofía de la naturaleza y la mitología proporcionaban en todo caso modelos tópicos pero nunca se captaban como fuerzas vivas. Tampoco el Romanticismo español supo captar la idealización del espíritu griego que parte de Winckelmann; «en el mejor de los casos se cultivaba la melancolía de las ruinas de un pasado desaparecido, cuyas repercusiones espirituales no se lograba comprender» (Rukser, 1977: 238). Su incondicional adscripción al clasicismo francés había provocado tal incomprensión del legado arcaico y sumergido de la Grecia referida por Goethe y celebrada por Nietzsche en su naturaleza dionisíaca.

La preocupación por Goethe, por Nietzsche y por la romantización de la mediterraneidad griega no se relaciona, pues, con el Romanticismo español, sino con la crisis interna del mundo hispánico alrededor de 1900. De modo semejante a la manera que el espíritu alemán había resuelto su crisis un siglo antes, el espíritu español quiso entonces afrontar los problemas de la nación siguiendo el vitalismo de los griegos impulsores de facultades creadoras. Goethe fue su gran autoridad moral, un intelectual responsable para defender la vida humana superando el cabo de las tempestades como artista cabal que educa para la libertad. Sus ojos de naturalista han enseñado a las venideras generaciones románticas que el arte aprende de la naturaleza su genuina perdurabilidad, consistente en la organicidad armonizadora de contrarios para lograr unidad en la variedad.

La difusión en España de tal poética vitalista de la naturaleza a partir del ejemplo de los clásicos griegos tuvo especial suerte en la adaptación de la noción de «Naturphilosophie» teorizada por Schelling y seguida por Krause. Como es sabido, gracias al apogeo de la escuela krausista durante los perio- 
dos republicanos de los albores del siglo XX, el vitalismo romántico influyó decisivamente en el mundo intelectual español. No obstante, el primer movimiento que esgrimió voluntariamente las teorías románticas de Jena con objeto de fundar un proyecto regenerador del país fue la escuela estética de Barcelona, de acuerdo con el juicio genealógico de Azorín (1963: 1300): «Nótese que por la puerta de Cataluña han irrumpido en España las novedades literarias o filosóficas. El Romanticismo penetró en España por Cataluña; la filosofía escocesa, igualmente; del mismo modo, el Naturalismo, y las primeras nociones de Nietzsche».

En el ambiente de la Renaixença de finales del siglo XIX surgieron eminentes polígrafos que rescataron y sistematizaron la teoría estética de los románticos alemanes, entre quienes destacan Milà y Fontanals y su discípulo Menéndez Pelayo, y ciertos escritores difundieron las obras de los grandes artistas y pensadores del Romanticismo, entre quienes destaca la primera traducción de Nietzsche por parte de Maragall así como su fervor poético por Goethe, de quien aprendió la visión interior del mar griego de los clásicos como absoluto literario donde encontrar el sentido topográfico de la razón de ser de su pueblo.

\section{LO GRIEGO, ABSOLUTO LITERARIO DEL ROMANTICISMO ALEMÁN}

\subsection{El viaje iniciático a la antigüedad grecolatina}

Los románticos alemanes hallaron en la antigua Hélade el modelo de inspiración ideal para la educación de hombre. El absoluto griego constituía un proyecto estético y político, pues, por un lado, ofrecía la depuración de ser estético con patrones de belleza virtuosa plasmada en la naturaleza que invitaban al artista a pensar «como los antiguos» (desarrollar un estado de contemplación interior de lo bello en la naturaleza para así trascender a su dimensión divina); y por otro, proporcionaba la autoafirmación nacional que necesitaba su esfuerzo por resucitar en Alemania la clasicidad genuina.

Goethe viajó a Italia para inspirarse en la cultura mediterránea de la antigüedad grecolatina. Llegó a Roma en 1786 con afán de relajación y de contagio intercultural entre norte y sur, lo romántico y lo clásico, y pronto disfrutó del humanismo sensual de la ciudad de los césares, de la hospitalidad de sus habitantes y de la paz octaviana de sus tesoros artísticos. Sus templos antiguos se le revelaron como monumentos del pueblo que antaño los edifi- 
cara y de su visión de mundo, y comprendió cuán distante estaba la arquitectura neoclásica de su belleza fundada en leyes naturales arcanas. Fue de su magna superioridad frente a las imitaciones como supo extraer la ley morfológica por la que perdura el arte y se vuelve clásico: la esencia armoniosa y lógica que refleja el organismo mundial, su unidad en la variedad.

Cansinos Assens ha subrayado en su prólogo a las Obras completas de Goethe que Italia le brindó los placeres meridionales del tacto: «Goethe necesita tocar las cosas, sentirlas palpitar bajo su mano, percibir la fuerza bajo la forma y sacar con el tacto un vaciado ideal de los contornos» (Cansinos Assens, 1991: 122). Y de esta relación sensitiva con la cultura mediteránea, el poeta romántico comprendió que allí se hallaba la cuna del genio, y por ello estudió su proceso artístico. En suma, el arte nacido en reflejos y travesías por el mar amniótico grecolatino donde Homero ideara la Iliada y la Eneida le enseñó a teorizar no tanto al pie de la regla cuanto a hombros del espíritu creativo.

\subsection{Inspirarse en el espíritu del todo}

A principios del siglo XVIII, la Universidad de Jena reunió a los grandes ideólogos del Romanticismo alemán con el proyecto de aunar teoría y práctica en favor de un proyecto liberador del pensamiento natural (la imaginación) y de la educación del hombre por una mitología sublime. La filosofía de la naturaleza postulada por Schelling fue el argumento fundamental para justificar la teoría del genio artístico como una dimensión inconsciente del propio yo infinito que, de modo natural, sabe reencontrarse consigo mismo en el objeto y, por ello, genera lo absoluto (unión de espíritu y materia, conocimiento y acción, lo universal y lo particular) (Schelling, 1996). Goethe fue el primero en tomar dicha teoría para su poética de la creación literaria, y su perspectiva vitalista también fue seguida por Nietzsche y por Krause.

El genio artístico contacta con el espíritu del ideal grecolatino, no con su literalidad. Quienes solo imitan sus formas exteriores, lo trivializan al desposeerlo de su sentido estético en el alma del contemplador. En cambio, quienes dialogan con él desde su espíritu lo dignifican estéticamente en su humanismo. Frente a la ciencia mecanicista de la razón analítica, el idealismo romántico desea convertir de nuevo a la naturaleza en patria del hombre. Con este fin reivindicativo de la autenticidad clásica afín al proyecto goethiano, Friedrich Schlegel escribió su ensayo Sobre el estudio de la poesía griega, donde expuso los prolegómenos de una nueva actitud creativa 
consistente en inspirarse libremente en el espíritu del todo, lo que él denomina «la pura grecidad» (Schlegel, 1995: 139).

El proyecto del genio romántico inspirado en el espíritu del todo que abanderó Goethe se apoyaba en las Reflexiones sobre la imitación del arte griego en la pintura y la escultura que hacia 1755 había escrito Winckelmann en atención al influjo de la geografía marítima y su clima en la constitución del antiguo arte griego, cuya noción de belleza ideal expresa un ethos grande y equilibrado que se constituyó en credo del clasicismo. Allí explicaba la noble sencillez y la serena grandeza que hace superiores a las obras de arte griego con una metáfora marina: «Así como las profundidades del mar permanecen siempre en calma por muy furiosa que la superficie pueda estar, también la expresión en las figuras griegas revela, en el seno de todas las pasiones, un alma grande y equilibrada» (Winckelmann, 1987: 36).

Goethe reconoció haber aprendido de Winckelmann que la mejor inspiración en los clásicos debe tener perspectiva holística y sensible a los procedimientos que aquellos usaban para inspirarse (Goethe, 1991: 1013-1030). Por tanto, si Homero tuvo al Mediterráneo por maestro, el poeta romántico hará lo mismo: no escribirá sobre el mar como producto literario sino con la estrategia imaginativa que aquel adoptó ante dicho paisaje, es decir, buscando en el mar el espíritu de todo. La mirada poética no es naturalista sino íntima: no objetualiza el mar sino que dialoga con su espíritu armonioso para aprender de la naturaleza el oficio de crear belleza.

Navegar hacia Grecia con ansias de rescatar su legado para la modernidad requiere lograr la misma hazaña que Homero: vencer el dualismo Naturaleza / Arte en el espejo interior que identifica la mirada del alma y la de sus profundas aguas. Solo así puede fundarse una cultura auténticamente moderna a partir de la antigua herencia griega, como bien indagó Goethe en su ideal conjuntivo entre la poesía de los antiguos y los modernos. También Friedrich Schlegel defendió este ideal en el fragmento 149 de la revista Athenäum: «cuando se descubra el punto de vista y las condiciones de la absoluta identidad entre Antiguiedad y Modernidad, que fue, es o será, podrá decirse que está concluido al menos el contorno de la ciencia, y que ya puede pensarse en el desarrollo metódico» (Schlegel, 1987: 139). Tal método se refería al afán por lograr la unidad del arte como una obra reciclable y perfectible gracias a la capacidad reflexiva que concede a la acción poética. En este sentido, Walter Benjamín ha destacado la audacia teórica de Schlegel al posicionar el absoluto literario como médium o pensamiento especulativo abismal que engendra su propia forma mirándose a sí misma en profundidad 
ilimitada (Benjamín, 1988: 63-65). El absoluto literario es la poesía como tal y su arte no es otra cosa que la fuerza viva de la naturaleza que se contempla a sí misma. Así son las pupilas del artista que reflejan el mar donde identificaron su propia emoción.

Schlegel concibió la belleza romántica como principio productor del arte. La belleza no reside en el objeto ni en la psique del contemplador, sino en la obra misma obrándose. Géneros y mitos se hallan en danza por el método de la metamorfosis poética que transporta al caos originario de la naturaleza humana en su eterno devenir. Lo absoluto mediático teorizado por Schlegel sustituye el hacer obediente de la mimesis por la socialización libre de la poiesis que da cuenta del ingenio humano. En su libro Poesía y filosofía se indica que su expresión idónea es el Witz, la facultad mental de reunir elementos heterogéneos en una paradoja de creación libre (Schlegel, 1994: 48). Así trabaja la retórica de la ironía empleada en resaltar lo bueno y grande del ser humano. Por ella es posible procurar la educación estética de sí cultivada por los griegos con la inteligencia reflexiva que subraya el dinamismo de la vida al tiempo que deconstruye la presunta validez de los hábitos y lugares comunes y las definiciones estáticas y descontextualizadas.

\subsection{El mar, espejo de melancolía}

$\mathrm{Al}$ igual que los escritores, los pintores románticos también defendieron que el concepto de naturaleza debe ser entendido en función del concepto de mirada interior. Caspar David Friedrich en su breve disertación «La voz interior» propuso cultivar el arte del recuerdo y de la imaginación para captar con sentimiento el alma de las cosas: «la imagen solo debe insinuar, y, ante todo, excitar espiritualmente y entregar a la fantasía un espacio para su libre juego» (Friedrich, 1987a: 53). El artista genera imágenes desde el sueño y sueños desde las imágenes. El verdadero arte parte, a su juicio, del inconsciente del artista, traspasa las esferas de la conciencia del emisor y del receptor, y finalmente se aloja poéticamente en el inconsciente de quien ha contemplado la obra.

De su técnica pictórica afirmó su discípulo Carl Gustav Carus (1987: 99): «No empezaba un cuadro hasta no tener su imagen viva ante el alma». La voz del interior es su talento estético. Y cuando el pintor lo descubre en sí, se entrega al absoluto artístico: «no se dispuso el hombre como modelo necesario del hombre, sino que su meta es lo divino, lo infinito. ¡Es al arte y no al artista a lo que hay que aspirar! El arte es infinito, finito es 
todo artista, toda destreza, todo saber» afirma Friedrich en su breve ensayo «Sobre arte y espíritu artístico» (Friedrich, 1987b: 132-133). Para él y sus discípulos la infinitud es la esencia divina del arte.

«Monje junto al mar» es un cuadro emblemático para materializar el proyecto romántico del hombre identificado con una naturaleza religada en su interior como afán de infinitud. Friedrich pintó al monje solitario y diminuto ante un paisaje inmenso de tierra, cielo y mar en brumas, que parece todavía más vasto y sublime ante la imaginación porque, como advierte Honour, pertenece a la «incertidumbre» (Honour, 1984: 79). La obra fue objeto de un comentario no menos poético por parte de Kleist tras observarlo en la exposición de Berlín de 1810, el cual interpreta al monje como un ser que, falto de vida, la percibe en el zumbido de la pleamar y al cuadro en sí como una exigencia sentimental del propio espectador: «Era así yo mismo el capuchino y era el cuadro la duna; pero aquello que yo debía mirar con anhelo no estaba: el mar» (Kleist, 1987: 135).

Tras recorrer la estructura iconológica de las pinturas de Friedrich, Argullol deduce que el maestro se especializó en una mirada reflexiva sobre la naturaleza, que es contemplación de la contemplación, que «introduce al espectador en un mundo cuya realidad se confunde con la subrealidad del sueño» (Argullol, 1987: 69). Interpretamos así a Kleist como el espectador que, identificándose con el monje que representa al contemplador absorto por el embrujo del paisaje, entra en un estado de ensoñación mediadora entre el ojo y la naturaleza. Su soñar despierto no se ha entregado a la contemplación, sino a la metacontemplación, al abismo abstractivo de lo físico; contemplación especial que le hace mirar su interior y percibir la nostalgia romántica, esa subjetividad insatisfecha que viaja para liberar su espíritu del asfixiante aire de limitación.

\subsection{El Mediterráneo dionisíaco de Nietzsche}

Al igual que Goethe, Nietzsche descubrió en el Mediterráneo la fuerza estética de lo sublime cuando viajó hacia Italia para vivir gozosamente y hacer poesía (Ross, 1994: 623-625). Desde su juventud, Nietzsche se había mostrado afín al absoluto literario del mar grecolatino. En mayo de 1868, pronunció su lección inaugural «Homero y la filología clásica» con deseo de romantizar la filología futura deconstruyendo la contemporánea en la cual advertía un pernicioso separatismo entre filología y arte debido a la soberbia de progreso disciplinar que imperaba en el ámbito universitario, donde se 
aludía al helenismo como una perspectiva superada. Este fue el motivo de su viaje más allá de la minucia erudita en busca del espíritu creativo de las obras maestras helénicas.

Como un pájaro que viaja hacia espacios lejanos del mar, en Aurora describió la experiencia estética de lo absoluto inconmensurable como si de un naufragio se tratara (Nietzsche, 1985b: 856):

Todo es mar, nada más que mar, mar y mar. ¿Dónde queremos ir? ¿Queremos atravesar el mar? ¿Adónde nos arrastra esa pasión potente que a toda otra pasión se sobrepone? ¿A qué ese desesperado vuelo hacia el punto en que hasta ahora todos los soles declinaron y se extinguieron? Se dirá algún día de nosotros que navegando siempre hacia el Oeste esperamos llegar a unas Indias desconocidas, pero que nuestro destino era naufragar en lo infinito.

El genio nietzscheano hurgó en la genealogía presocrática de los griegos hasta encontrar su sima pasional, la Atlántida abismada en sus aguas, lo africano. La vida se derrama en el calor africano de los ritos dionisíacos, en las orgías del helenismo primitivo donde los hombres curtidos por el sol y la energía del ambiente náutico pasan al estado del metal y se comportan como atlantes sumergidos en los abismos de la conciencia. En El origen de la tragedia argumentó que conocer la facultad dionisíaca de un pueblo implica contar con su «mito trágico». Y se lamentaba de la evolución del espíritu alemán hacia una cultura sin mitos, anclada en los males agresivos de la dialéctica. Por ello, con impulso romántico defendió a los presocráticos que se sobreponen al horror de la existencia porque su misma existencia es permanente creación de ficciones intensificadoras de la vida. Aquellos griegos fueron los artistas paradójicos que supieron hacer de la propia existencia un fenómeno estético, un arte alegre, valedero para aprender a olvidar. Y Ulises representa el ideal griego en su doble faceta afirmativa de la ficción como pasión vital y de la existencia aun en sus aspectos más dolorosos, efecto de su terquedad heroica y de las argucias de su ingenio (Nietzsche, 1985b: 779).

Lo patético, manifestación de lo sublime como pasión o resistencia ante el dolor, fue recuperado por Nietzsche con la pretensión de fundar a partir de su fuerza paradójica una nueva ciencia de la estética. Apolo y Dionisos son sus protagonistas, pero no para contraponerlos como dioses enemigos, sino para mezclarlos en el pulso de la tragedia. La fusión nietzscheana de lo apolíneo con lo dionisíaco no es otra que la de lo bello con lo sublime, la 
del olímpico y sereno desfile de lo clásico con la del ebrio y satírico ditirambo de los presocráticos. García Gual ha valorado el alcance de tal propuesta: «Al destacar en la esencia de lo trágico la superación del conflicto de ambos principios, Nietzsche lanzaba una mirada nueva sobre el mundo antiguo, mucho más profunda que la visión que se contentaba con la luminosa serenidad (o «jovialidad», Heiterkeit) de la imagen más tradicional del clasicismo» (García Gual, 2000: 93). En efecto, la nueva mirada de Nietzsche afirmaba rotundamente el vitalismo trágico del mundo helénico. Detrás de la calma y dignidad elogiadas por Winckelmann, vio la lucha de Heráclito, el uso griego de los instintos tras una sublimación que no se separa de la naturaleza ni de la vida, antes bien pone al hombre trágico ante las espantosas verdades de la existencia humana para asumir su heroísmo auténtico — patético- desde el momento en que apuesta por la vida a pesar de la agonía que acarrea.

En Goethe encontró un ejemplo digno de admiración. Alegó en El crepúsculo de los ídolos que el maestro de Weimar fue, como los griegos, libre artista de sí mismo: «se disciplinó a sí mismo para llegar a ser integral» (Nietzsche, Crepúsculo 1254). No obstante, estimaba que Goethe no comprendía bien a los griegos, pues la realidad fundamental del instinto helénico es, según Nietzsche, su voluntad de vivir: «¿Qué era lo que el heleno buscaba por medio de esos misterios? La vida eterna, el eterno retorno a la vida, el porvenir prometido» (Nietzsche, 1985c: 1260). Y ni Winckelmann ni Goethe hubieran admitido la esencia patética del culto dionisíaco: «Para que exista la alegría eterna de la creación, para que la voluntad de vivir se afirme eternamente por sí misma, es necesario también que existan los dolores del parto. La palabra «Dionisos» significa todo esto. No conozco simbolismo más elevado que este simbolismo griego de las fiestas dionisíacas. El más hondo instinto de la vida, el de la vida futura» (Nietzsche, 1985c: 1261).

En la Universidad de Basilea Nietzsche impartió docencia sobre los presocráticos, cuyas lecciones constan en La filosofía en la época trágica de los griegos. Su orientación era diametralmente innovadora: Empédocles, Demócrito y sobre todo Heráclito, maestro en aforismos, le enseñaron a perseguir la sana vitalidad del amor fati en un nuevo entendimiento de la Antigüedad que sirviera a la propia vida. Así que su viaje a los orígenes de la cultura griega fue una aventura hacia el destino de la naturaleza, al eterno retorno de la vida en su verdad. 
La verdad de la vida es múltiple y cambiante, pues incluye el instinto de la duda, de la espera y de la sospecha; el experimento de la «gaya ciencia»; la circularidad trágica y sensual como el flujo y reflujo de las olas que dimana de aquella voluntad de devenir que irradia el cuerpo comparable a un mar inmenso. En este sentido, son reveladoras las palabras de Jarauta: «Este doble instinto, sobre el que se levanta la voluntad trágica, responde al ritmo interno de la Physis, y no es casual que Nietzsche modele estos Kunsttriebe (impulsos artísticos) a partir de los estadios fisiológicos de embriaguez (Rausch) y sueño (Traum), entendidos como "estadios artísticos inmediatos de la naturaleza"» (Jarauta, 2000: 109).

A su juicio, la experiencia de lo patético puede ocasionar en el hombre dos tipos de carácter: el reactivo y vengativo a partir del sufrimiento, que correspondería al pesimismo de Shopenhauer y de Wagner; el agradecido al porvenir exuberante de vida por la que el sujeto soporta el sufrimiento, que correspondería a un pesimismo trágico derivado de Dionisos. A este último atribuyó esa voluntad del arte que anhela resaltar el «sentido de la tierra». Así que su romanticismo, forjado en la ironía de la coincidencia opositorum que es profundización en lo sublime, se compagina con las ideas de Schlegel y de Novalis sobre lo infinito fragmentario porque «el fragmento se abandona a la inmediatez y se deja orientar por la ocurrencia, hace despuntar el Witz» (Lynch, 1993: 73).

Nietzsche deseaba regenerar Alemania con el ejemplo griego. Así lo afirma en El origen de la tragedia: «Es de desear que nadie trate de debilitar nuestra fe en un renacimiento inminente de la antigüedad helénica, pues ésa es la única esperanza de regeneración y purificación del espíritu alemán» (Nietzsche, 1985a: 582). Es la experiencia atlante de abismarse en un océano de tormento infinito, la suprema dicha de sumergirse en la claridad mediterránea como héroes meditada en Humano, demasiado humano (Nietzsche, 1985d: 2230):

El peligro del retorno a lo Asiático amenaza siempre a los griegos, y se creería verdaderamente que de vez en cuando llegaba sobre ellos como un sombrío desbordamiento de impulsiones místicas, de salvajadas $y$ de obscurantismos elementales. Los vemos sumergirse; vemos a Europa arrastrada y sumergida por la ola, pero reaparecen siempre a la superación como buenos nadadores y buzos que son los hombres del pueblo de Ulises. 


\section{LA RECEPCIÓN DEL ABSOLUTO LITERARIO ROMÁNTICO EN LA POESÍA DE LA RENAIXENÇA CATALANA. EL EJEMPLO DE JOAN MARAGALL}

\subsection{Krausismo y Renaixença}

El mar como metáfora del absoluto literario que hacia 1800 teorizaron los poetas del Romanticismo alemán recobró vigencia entre los artistas españoles de 1900. Gracias a la introducción del sublime romántico en nuestro país, uno de los aspectos más significativos de la literatura española de aquellos años fue la adhesión a un humanismo de carácter universal que apostaba por un vitalismo ideológico que soportase el doloroso horizonte de expectativas tras la pérdida de Cuba, símbolo de la grandeza española ya extinguida, y que pretendiera recobrarlo con el ingenio heroico del pueblo. Azorín indicó en su ensayo «La generación de 1898» (Azorín, 1963: 11431146) que dicho evento se convirtió en catalizador de una fuerte reacción cultural que pretendía escudriñar los impulsos idealistas fin de siècle para sacar a flote la personalidad moral distintiva del español y regenerarla de su abatimiento. Con este ánimo, y aunque parezca contradictorio, la aportación de bibliografía extranjera fue un hecho decisivo para suscitar el patriotismo.

La circunstancia cultural en la que se afirmó el proyecto regenerador de España se remonta hacia mediados del siglo XIX, cuando comenzaron a propagarse con profundidad reflexiva las doctrinas estéticas procedentes de la Alemania romántica. La difusión del pensamiento alemán sobre la filosofía de lo bello fue iniciada por dos núcleos universitarios coetáneos: uno madrileño, enarbolado por Sanz del Río; el otro barcelonés, liderado por Milà y Fontanals. El primero, tras estudiar en Heiderberg, trajo a España el idealismo trascendental de Krause que seguía la visión orgánica de la naturaleza de Schelling y la educación del gusto estético como un bien moral de la cultura. El segundo, siguió las teorías de Schlegel para reivindicar una estética del clasicismo desde una perspectiva romántica de lo sublime moral donde tiene cabida la idea nietzscheana de lo patético suscitada por el mito náutico de Dionisos (Caro Valverde y González García, 2012: 161-162). También importa señalar que en 1862 se fundó en Barcelona la revista $L a$ Abeja con el fin de difundir en la península la cultura germánica publicando trabajos estéticos y literarios del Sturm und Drang, y que su labor fue continuada a partir de 1875 con la Revista Contemporánea de Madrid (López Morillas, 1980: 103-105). 
A principios de siglo XX, triunfó en Madrid el programa pedagógico del krausista fundador de la Institución Libre de Enseñanza, Giner de los Ríos, mientras que en Barcelona el contacto con el Romanticismo alemán se produjo desde fuentes directas, pues aumentó el interés por la obra goethiana entre los literatos catalanes. Joan Maragall vertió a la lengua catalana múltiples lieder y, como caudillo de la Renaixença que pretendía superar el desfase estético de la literatura catalana con respecto a las literaturas europeas, comunicó su entusiasmo a poetas inmediatos como Eugenio D’Ors, Ramón Cansinos Assens y Alfonso Reyes. También debe atribuirse a Maragall la iniciativa de rescatar a Nietzsche con ecuanimidad desprejuiciada, más allá del escándalo que provocaba su filosofía anárquica: «empieza a interesar más la verdad de sus ideas que la fuerza centrífuga por ellas desencadenada» (Sobejano, 1967: 138). Y quienes le siguieron tomaron el camino en dos sentidos: anarquista o aristócrata. El primero, lo recorrieron alrededor de 1898, impelidos por el desastre nacional que advino con el mundo de la Restauración. El segundo, se desarrolló una década después, con pensadores que retomaban la inspiración nietzscheana desde una perspectiva regeneradora más filosófica que política.

Joan Maragall fue el primer traductor de Nietzsche en España. En los números 20 y 21 de L'Avenç (31 octubre-15 noviembre 1893) publicó en lengua catalana varios fragmentos de cada una de las cuatro partes de Així va parlar Zarathustra, que versaban sobre el Superhombre, la voluntad de crear y lo sagrado de la risa. La intención del poeta barcelonés era comunicar las líneas fundamentales de este novedoso pensamiento sobre la vida desde una óptica sana, idónea para renacer con optimismo de las cenizas de nuestras sociedades. Prudentemente, recuperó al Nietzsche sociólogo y poeta y evitó al filósofo anticristiano. En efecto, si bien Maragall había evolucionado desde una tendencia modernista hacia el vitalismo nietzscheano, hacia 1900 su actitud heráldica abandonó su entusiasmo inicial, y comenzó a ver como delirio y tragedia lo que antes había considerado saludable vigor. Gonzalo Sobejano (1967: 85) ha razonado su distanciamiento de Nietzsche como efecto de su convicción creciente en la espiritualidad cristiana.

De modo independiente a las tendencias catalana y madrileña, pero inscrito en el mismo plan de renovación cultural ligada al vitalismo romántico del que fuera heredero Nietzsche, desde la generación de 1910 cabe destacar la labor difusora de los valores culturales germánicos en España a través de Revista de Occidente por parte de Ortega y Gasset, pues estaba íntimamente 
compenetrado con la vida intelectual alemana desde que hiciera sus estudios en Marbur. Ciertamente, este nietzscheanismo de Ortega es patente, tal y como analiza Sobejano, en varios puntos: «perspectivismo; valoración de la vida; ética individual, social y política de la nobleza (aristocratismo); ideas estéticas; actitud, intención y trascendencia de la labor filosófica» (Sobejano, 1967: 541).

Con la voluntad de poder nietzscheana, la nueva literatura española vuelve al romanticismo renovado sin negatividad, sin los desfallecimientos de Bécquer, sin la pistola de Larra. Razón tenía Guillén Salaya cuando afirmaba: «Nietzsche, que era el gran romántico, el gran renovador, sacudió a latigazos la modorra de las masas - y de las aristocracias - y les infundió el espíritu dionisíaco que había de nuevo de animar al mundo» (Guillén Salaya, 1931: 48). La nueva literatura, que a su juicio comprende el período 1900-1928, reivindica un perfil dionisíaco jovial procedente del encanto mítico del teatro presocrático.

Al proyecto de la Renaixença hay que añadir la influencia decisiva de la estética de Hipólito Taine, quien en sus Ensayos de Crítica e Historia sostuvo que una obra depende de su medio: «Observad la manera de forjarse esa humanidad. No sólo el artista ha tomado de ella los materiales en los hombres de su país y de su tiempo, sino que además los ha combinado únicamente para expresar mejor algún carácter esencial de su raza y de su época» (Taine, 1953: 967). A su juicio, todas las obras maestras expresan en su fondo las potencias soberanas de la Naturaleza: «Dos fuerzas principales determinan los pensamientos y los actos de los hombres: una, la naturaleza, otra, la cultura. Considerad alternativamente esas dos fuerzas en las obras de arte que las hace visibles» (Taine, 1953: 968). Taine defendió la idea de que cada paisaje tiene su alma o lo que los antiguos llamaban «genius loci» para indicar que su aspecto exterior traduce su interior de modo movible y sugestivo por su semejanza con la fisonomía humana que revela su psicología. Y con lucidez observó que este comportamiento natural fue perseverantemente imitado por los románticos, y más que ningún otro por Goethe, cuyo eclecticismo era consecuente con su afán de experimentar la vida multiforme. Leer a Goethe desde la perspectiva de Taine permitió a los poetas de la Renaixença inspirarse en las teorías y textos literarios del Romanticismo alemán sin despojarse de su identidad mediterránea tradicional. Antes bien, convirtieron el mar donde se miran los habitantes de Cataluña en absoluto literario de las aspiraciones artísticas y vitales de su canto. 


\title{
3.2. Joan Maragall, traductor del vitalismo romántico
}

En la obra literaria de Joan Maragall se unen vida y poesía. Su poesía es vital y compleja porque - como de él ha escrito Dámaso Alonso en su ensayo «Lo infinito y lo realísimo (y su molde) en la poesía de Maragall» (Alonso, 1961: 79-133)— desborda ansias de infinitud. Así pues, en su poema «La oda infinita» dice haber comenzado una oda a la naturaleza para venerarla en su belleza humana, que es plena e inconmensurable (Maragall, 1960: 65):

\section{Tinc una oda començada} que no puc acabar mai.

El mar también es figura de su poética del infinito creativo inspirada en la experiencia de la naturaleza. Una excursión de Maragall al paisaje marítimo de Tossa en la Costa Brava realizada en 1905 fue la que inspiró su poemario Vistes al mar con una actitud contemplativa que recuerda a los paisajes de Friedrich, pues logra que «el recuerdo de la vivencia transite hacia una especie de ensoñación» (Tort y Donada, 2009: 160). Admirar en su viveza las montañas verdes y escarpadas frente al mar inmenso y bravo educó su emotividad existencial y su verdad interior.

Vistes al mar es una sucesión de estampas tomadas de la costa del Maresme donde se celebran los instantes de plenitud de un mar agitado, primitivo y brutal, que por su iteración y vitalismo condensa la eternidad y se convierte en ejemplo mismo del arte patético de los románticos (Maragall, 1960: 110):

\author{
El vent se desforma \\ $i$ tot el mar canta. \\ Mar brava, mar verda, mar escumejanta! \\ L'onada s'adreça, \\ venint s'ageganta, \\ avença i s'acosta \\ callada que espanta. \\ L'escuma enlluerna, \\ el sol l'abrillanta, \\ l'onada l'esberla \\ i cau ressonanta.
}

El poeta se mira a sí mismo en el mar que se enfrenta a la roca buscando su fondo vital y valiente. Su oficio se forja entonces en el acto originario de la naturaleza salvaje que le dota de fuerza sentimental, grandeza ideológica, hondura imaginativa y nobleza de lenguaje para dar sentido humanista a su 
obra. La naturaleza marina, y en especial la fuerza del mar, le procuran el canto enérgico al superhombre como verdad regeneradora de su pueblo. Y en este sentido, la voluntad artística de Maragall (1960: 155) se deslindó del decadentismo de la tendencia modernista en boga que celebraba las sutilezas de la belleza triste y se aproximó a la de los grandes forjadores del Romanticismo, en quienes encontró ejemplo optimista y sano para plantear el espíritu homérico del hombre capaz de regenerar la sociedad más allá de sus miserias y totalitarismos.

El haber traducido a Novalis, a Nietzsche y, profusamente, a Goethe ${ }^{1}$ es un hecho significativo en tal formación poética de Maragall, hasta el punto de que cabe concebir su escritura como un movimiento pendular que abarca desde el helenismo heredado de Goethe al cristianismo que predicara Novalis, llegando en lo helénico a la exaltación dionisíaca augurada por Nietzsche con una posición cercana al ideario del movimiento krausista. No en vano Joseph Pijoan y Joseph Soler i Miquel, de gran ascendencia moral sobre Maragall, habían sido discípulos de Giner de los Ríos.

El primer reflejo de Nietzsche en el mundo hispánico apareció gracias a un artículo escrito por Maragall en febrero de 1893, que, tras ser rechazado por el Diario de Barcelona, finalmente, en la necrológica del pensador alemán, encontró publicación en $L^{\prime}$ Avenç en junio del mismo año con el pseudónimo de «Panphilus». Su actitud es acogedora y entusiasta: lo recibe como afirmador de la voluntad optimista y de la nobleza aristocrática: «Nietzsche aixeca bandera devant de l'idea determinista pessimista democratica que avui està apoderada de tot; i afirmat la lliure voluntat umana, desencadena la Wille zur Macht (voluntad de poder) con a grand força impulsora de la vida» (Maragall, 1973: 300). Admira la plasticidad de su estilo como torrente de poesía emanada de un naturalismo desnudo. Su lectura le provoca una sensación semejante a quien, ya en la cima de una montaña, respira el aire puro de las alturas cargado de oxígeno y de fuerte olor a pinos. En términos mediterráneos nos traduce la imagen del conocido cuadro de Friedrich «Viajero sobre el mar de nubes», porque el Nietzsche de Maragall es profundamente romántico, necesita la fuerza vital del contrasentido

\footnotetext{
1 Estas son las traducciones de las obras de Goethe a la lengua catalana ordenadas cronológicamente por Udo Rusker (1977: 287-319): Els corresponsables (1890), Ifigenia en Táuride (1898), Eridón y Amina (1900), Margarideta (1903), Els Disperses (que contiene poemas de Elegies romanes, Alexis $i$ Dora, El Nou Pausias, La Florista, Mignon, La copa del Rei de Thule, La roseta de Bardissa, Nit nupcial, Epigrames venecians, Dedicatoria, Fragmentos de Fausto) (1904), Pensaments de Goethe (1910), y Goethe (antología para las escuelas de Cataluña, 1932).
} 
como lógica — paradójica — de su pensamiento abocado al infinito. Nietzsche le fascinaba porque su nuevo código de valores se convirtió para muchos en una especie de Evangelio, bajo cuyo signo los intelectuales se esforzaban en renacer. Desde el Diario de Barcelona, donde colaboró a partir de 1890, explicaba la obra de Nietzsche a sus lectores, y a menudo esgrimía los argumentos del filósofo para criticar a la clase social burguesa a la que él mismo pertenecía; como fue el caso destacado de sus artículos después de la Semana Trágica. De ello extrajo Maragall una alta estimación ética de la vida. Tradujo con acentos cristianos elementales desprovistos de violencia las enseñanzas nietzscheanas de Zaratustra cuando proclamaba que todo lo que tiende a deprimir la fe en la definitiva bondad de la vida es inmoral. Con otras palabras, él profesaba una fe en la vida porque tenía un fin de bien entusiasta y solidario.

Más aún que de Nietzsche, Maragall merece ser calificado como el apóstol catalán de Goethe durante la Renaixença. Su admiración por el maestro de Weimar le acompañaría toda su vida. Su entusiasmo juvenil con el Werther le impulsó a aprender el idioma alemán para poder leer a Goethe en el original y posteriormente traducirlo. No solo tradujo al catalán textos goethianos como Faust, Ifigenia a Tàurida, Eridon i Amina y las Elegies romanes, sino que los asumió a modo de estímulos estéticos, a la vez clásicos y románticos, según ha analizado Roser Campi (2000: 27-36). De hecho, como vehículo de tales obras maestras emanadas del escritor romántico más universal, el catalán quedaba ennoblecido por encima de la típica consideración de lenguaje rústico o menestral propio de la literatura localista. Incluso, además de traducirlo, escribió una obra teatral, Nausica en 1910, de inspiración goethiana y de tema homérico. Maragall supo transmitir a su generación la figura estética de Goethe como el modelo regenerador por excelencia por su cultivo universal de todas las facultades y el perfeccionamiento del propio ser. Con un espíritu ponderado a imitación del eclecticismo goethiano, estaba persuadido de que, en última instancia, todas las aguas se reunirían en un mismo caudal generoso. Por tanto, su teoría literaria fue corolario de estos puntos de partida, pues concibió la poesía pura como la intensificación de la vida expresándola. Al poeta se le revela esta intensidad como un «estado de gracia», y solo de este momento patético nace la palabra viva.

La poesía de Maragall muestra su temperamento romántico cuando expone la palabra como un don sagrado de virtud misteriosa. Cuando se depura en su vitalidad, la palabra refleja el ritmo claro del Universo. Y ello se consigue por la expresión sincera en ese estado de «gracia» o plétora vital 
de la vehemencia interior, ya que la manera personal de escribir surge en cada poeta de la entraña misma de la emoción. La palabra viva acude a los labios de modo espontáneo, interjeccional, destellos de cántico verdadero. Es acertada la aseveración de Enric Bou (1997: 13) «Novalis serví a Maragall per traçar el mapa d'una pàtria poètica», pues, como Novalis, Maragall sostuvo que la poesía es sustento e intensificación de la vida y germen de más vida. En consecuencia, más que un compositor de poemas, el poeta ha de ser un estimulador de vida. Y en el paisaje encuentra su cara sensible: frente a su cotidiana visión urbana de Barcelona, limitada por paredes y tejados, su fulgurante visión poética se desplaza a la naturaleza libre y se deja maravillar por el mar, espectáculo infinito de la creación divina. En Vistes del mar refleja ese asombro estremecido ante el vivo Mediterráneo desde la perspectiva de la visión espectacular de sus corrientes en puja: «Mar brava, mar verda, mar escumejanta!» (Maragall, 1960: 110).

\section{CONCLUSIÓN}

La poética de la imaginación romántica nacida de la estela del Sturn und Drang alemán encontró en la Renaixença catalana la primera recepción reflexiva del concepto fundamental de absoluto literario que hubo en España, ya que lo integraron en la acción creativa de la poiesis y no en la acción reproductiva de la mimesis, al acudir a él, no desde la confirmación de tópicos sobre lo telúrico y decrépito que un siglo antes habían mostrado los escritores románticos hispánicos, sino con el afán poético de regenerar a su pueblo por obra de la visión utópica de la literatura que despierta el ingenio procurador de lo bueno y grande del ser humano en la vida libre y paradójica de los símbolos.

En este sentido, la naturaleza inmensa del mar ha inspirado en las pupilas de los artistas genuinamente románticos la relación espiritual con su obra en busca de la armonía del todo sublime. Los poetas entregados a la contemplación del mar han mirado de frente su enigma - el tesoro que encierra en lo inmenso de su marejada y su fondo-y han aprendido así el absoluto literario, es decir, el pensamiento especular de la literatura que aprende de los procesos naturales el sentido orgánico y productivo de su propia teoría. En efecto, cuando la naturaleza se convierte en un espejo que revela los secretos de la mente del poeta, el ojo exterior despierta al ojo interior, y le permite bucear en el océano de la imaginación como un espectador de sí mismo inmerso en un ámbito sublime, enorme a la vez que fragmentario, promesa de infinita profundidad. 
Del magisterio de Goethe y de Nietzsche sobre la fuerza utópica y vitalista del mar Mediterráneo que dio razón de ser al pathos de la Grecia presocrática donde con audacia se curtió el ingenio de Ulises ante las zozobras de la travesía, los teóricos y poetas de la Renaixença aprendieron a romantizar la literatura con argumentos regeneracionistas que necesitaron sumergirse en una metacontemplación especular de su propio proyecto creativo tal y como los griegos se habían mirado en las aguas del Mediterráneo en busca la Atlántida, el origen diferido que invita al viaje incierto y aventurero de la imaginación. Así que, por mediación de la coherencia teórica que aquellos estetas y poetas catalanes asimilaron de la poética de la literatura del Romanticismo alemán, el sentido topográfico del mar de Homero se convirtió en la razón de ser del pueblo español.

En consecuencia, paradójicamente, el patriotismo de la Renaixença procede de influencia extranjera y su modernidad la aprendieron de la antigüedad clásica. Tal es el amplio espectro educativo de su humanismo, que se confirma en el ejemplo destacado de Joan Maragall, cuya obra también manifiesta el absoluto literario del genio romántico por efecto de su relación emocional con el mar. Maragall meditó desde la costa acerca de la fuerza especular y dionisíaca de la naturaleza marina y extrajo de ello la noción de «poesía pura» como un aprendizaje expresivo para la vida. Su obra es romántica no tanto por los tópicos a los que acude como por su entrega a las entretelas del tiempo, donde el presente es mediación sanitaria para que el pasado glorioso de un pueblo sea germen de vida futura que regenere a los pueblos modernos de sus contextos en crisis.

\section{REFERENCIAS BIBLIOGRÁFICAS}

ALONSO, D. (1961). Cuatro poetas españoles. Madrid: Gredos.

ARGULLOL, R. (1987). La atracción del abismo (Un itinerario por el paisaje romántico). Barcelona: Plaza \& Janés.

AZORÍN (1963). Obras completas. Vol. 9. Madrid: Aguilar.

BACHELARD, G. (1965). La poética del espacio. México: Fondo de Cultura Económica.

BENJAMIN, W. (1988). El concepto de crítica del arte en el Romanticismo alemán. Barcelona: Península.

BOU, E. (1997). «"La llum que ve del nord". Joan Maragall i la cultura alemanya». Quaderns: Fundació Joan Maragall 37, 5-14. 
El MAR, ABSOLUTO LITERARIO. LA INFLUENCIA DEL ROMANTICISMO...

CAMPI, R. (2000). «Joan Maragall i J. W. Goethe: la influència de l'escriptor alemany en el pensament civil». Els Marges 68, 13-49.

CANSINOS ASSENS, R. (1932). Los temas literarios y su interpretación. Madrid: Editorial V. H. Sanz Calleja.

- (1991). «Estudio preliminar». En J. W. Goethe, Obras Completas, vol. 1, 9-338. Madrid: Aguilar.

CARO VALVERDE, M. T. y MORÍN, E. (2008). «La pédagogie romantique de la Méditerranée dans les portraits d'Azorin et Miró». Scripta Mediterranea XXIX, 3-19.

CARO VALVERDE, M. T. y GONZÁLEZ GARCÍA, M. (2012). «El legado estético de Milá y Fontanals: del common sense al clasicismo romántico». Analecta Malacitana XXXIV 1, 153-168.

CARUS, C. G. (1987). «El taller de Caspar David Friedrich». En Fragmentos para una teoría romántica del arte, J. Arnaldo (ed.), 99-100. Madrid: Tecnos.

FRIEDRICH, C. D. (1987a). «La voz interior». En Fragmentos para una teoría romántica del arte, J. Arnaldo (ed.), 53. Madrid: Tecnos.

- (1987b). «Sobre arte y espíritu artístico». En Fragmentos para una teoría romántica del arte, J. Arnaldo (ed.), 132-133. Madrid: Tecnos.

GARCÍA GUAL, C. (2000). «Nietzsche, en el camino hacia los griegos». Revista de Occidente 226, 86-101.

GOETHE, J. W. (1991). Obras Completas. Vol. 2. Madrid: Aguilar; traducción de Rafael Cansinos Assens.

GUILLÉN SALAYA, F. (1931). Parábola de la nueva literatura. Madrid: Biblioteca Atlántico.

HONOUR, H. (1984). El Romanticismo. Madrid: Alianza.

JARAUTA, F. (2000). «Nietzsche: tragedia y filosofía». Revista de Occidente 226, 102-115.

KLEIST, H. W. v. (1987). «Sentimientos ante un paisaje marino de Friedrich». En Fragmentos para una teoría romántica del arte, J. Arnaldo (ed.), 134-135. Madrid: Tecnos.

LACOUE-LABARTHE, P. \& NANCY, J.L. (1978). L'absolu littéraire. Théorie de la littérature du romantisme allemand. Paris: Éditions du Seuil.

LYNCH, E. (1993). Dioniso dormido sobre un tigre (A través de Nietzsche y su teoría del lenguaje). Barcelona: Destino. 
LÓPEZ MORILLAS, J. (1980). El krausismo español (Perfil de una aventura intelectual). Madrid: Fondo de Cultura Económica.

MARAGALL, J. (1960). Obres completes, I, Obra catalana. Barcelona: Selecta; edición de Joseph Carner.

- (1973). «Nietzsche». Revista de Occidente 126, 299-303.

NIETZSCHE, F. (1985a). El origen de la tragedia. En Obras inmortales. Vol. 1, 467-604. Barcelona: Teorema; edición de Enrique Eidelstein, Miguel Ángel Garrido y Carlos Palazón.

- (1985b). Aurora. En Obras inmortales. Vol. 2, 615-856. Barcelona: Teorema; edición de Enrique Eidelstein, Miguel Ángel Garrido y Carlos Palazón.

- (1985c). El crepúsculo de los ídolos. En Obras inmortales. Vol. 3, 11691262. Barcelona: Teorema; edición de Enrique Eidelstein, Miguel Ángel Garrido y Carlos Palazón.

- (1985d). Humano, demasiado humano. En Obras inmortales. Vol. 4, 1895-2274. Barcelona: Teorema; edición de Enrique Eidelstein, Miguel Ángel Garrido y Carlos Palazón.

ROSS, W. (1994). Friedrich Nietzsche. El águila angustiada. Barcelona: Paidós; edición de Ramón Hervás.

RUSKER, U. (1977). Goethe en el mundo hispánico. Madrid: Fondo de Cultura Económica.

SCHELLING, F. W. J. (1984). Lecciones sobre el método de los estudios académicos. Madrid: Editora Nacional; edición de M. Antonia Seijo Castroviejo.

- (1996). Escritos sobre filosofía de la naturaleza. Madrid: Alianza; edición de Arturo Leyte.

SCHLEGEL, F. (1987). «Fragmentos del Athenäum». En Fragmentos para una teoría romántica del arte, J. Arnaldo (ed.), 137-144. Madrid: Tecnos.

- (1994). Poesía y filosofía. Madrid: Alianza; edición de Diego Sánchez Meca.

- (1995). Sobre el estudio de la poesía griega. Madrid: Akal; edición de Berta Raposo.

SOBEJANO, G. (1967). Nietzsche en España. Madrid: Gredos.

TAINE, H. (1953). Ensayos de Crítica y de Historia. Madrid: Aguilar; edición de Julio Gómez de la Serna. 
EL MAR, ABSOLUTO LITERARIO. LA INFLUENCIA DEL ROMANTICISMO...

TORT I DONADA, J (2009). «El paisaje existencial. Consideraciones sobre el valor geográfico de la obra de Joan Maragall». Boletín de la A.G.E. 51, 153-173.

WINCKELMANN, J. J. (1987). Reflexiones sobre la imitación del arte griego en la pintura y la escultura. Barcelona: Península; edición de Vicente Jarque.

Recibido el 8 de junio de 2013.

Aceptado el 19 de septiembre de 2013. 
